\title{
Bidirectional Tracking Robust Controls for a DC/DC Buck Converter-DC Motor System
}

\author{
Eduardo Hernández-Márquez $\mathbb{D}^{1},{ }^{1}$ José Rafael García-Sánchez $\mathbb{D}^{1},{ }^{1}$ Ramón Silva-Ortigoza $\mathbb{D}^{1},{ }^{1}$ \\ Mayra Antonio-Cruz (D), ${ }^{1}$ Victor Manuel Hernández-Guzmán $(\mathbb{D}),{ }^{2}$ Hind Taud $(D)$, \\ and Mariana Marcelino-Aranda $\mathbb{D}^{3}$ \\ ${ }^{1}$ Área de Mecatrónica, CIDETEC, Instituto Politécnico Nacional, 07700 Mexico City, Mexico \\ ${ }^{2}$ Facultad de Ingeniería, Universidad Autónoma de Querétaro, 76150 Querétaro, QRO, Mexico \\ ${ }^{3}$ SEPI, UPIICSA, Instituto Politécnico Nacional, 08400 Mexico City, Mexico \\ Correspondence should be addressed to Ramón Silva-Ortigoza; rsilvao@ipn.mx
}

Received 25 January 2018; Revised 17 April 2018; Accepted 10 May 2018; Published 23 August 2018

Academic Editor: Hugo Morais

Copyright (c) 2018 Eduardo Hernández-Márquez et al. This is an open access article distributed under the Creative Commons Attribution License, which permits unrestricted use, distribution, and reproduction in any medium, provided the original work is properly cited.

\begin{abstract}
Two differential flatness-based bidirectional tracking robust controls for a DC/DC Buck converter-DC motor system are designed. To achieve such a bidirectional tracking, an inverter is used in the system. First control considers the complete dynamics of the system, that is, it considers the DC/DC Buck converter-inverter-DC motor connection as a whole. Whereas the second separates the dynamics of the Buck converter from the one of the inverter-DC motor, so that a hierarchical controller is generated. The experimental implementation of both controls is performed via MATLAB-Simulink and a DS1104 board in a built prototype of the DC/DC Buck converter-inverter-DC motor connection. Controls show a good performance even when system parameters are subjected to abrupt uncertainties. Thus, robustness of such controls is verified.
\end{abstract}

\section{Introduction}

The electrical energy control with power electronic devices has been an important research topic during the last years [1]. Where the driving of new classes of motors has been possible thanks to the power electronics [2]. Likewise, the use of the control engineering and power electronics [3], among other areas, glimpses the possibility of achieving a driving more efficient of the new forms of electrical energy generation [4]. In that direction, the different forms of electrical conversion result very important in the energy processing. Thus, the appropriate supply of multiple applications of the new energy forms is achieved [5-10]. In such applications, some involving motion generations are found whose operation is reduced to the design of drivers for motors (see $[11,12])$. Among others, the DC motors have been benefited by the design of drivers based on DC/DC power electronic converters. Thus, according to the rotation of the motor shaft, works related to the control of DC/DC power converters-driven DC motors can be divided in two fashions: (a) with unidirectional rotation and (b) with bidirectional rotation. Thus, the state-of-the-art review is as follows.

1.1. Unidirectional Rotation. Lyshevski [11] proposed mathematical models for DC/DC power converters connected to DC motors. The topologies there considered were the Buck, Boost, and Cuk. Also, Lyshevski designed a nonlinear PI control for regulating the angular velocity of the DC/DC Buck converter-DC motor system. On the other hand, Boldea and Nasar [12] presented position, velocity, and torque controls to solve the regulation problem of DC/DC power converter-DC motor systems. Later, for the first time, Linares-Flores in [13] proposed a differential flatness-based control, an average GPI control, and a passivity-based control. These three controls solve the trajectory tracking 
task in the DC/DC Buck converter-DC motor system. Also, for the same system, Ahmad et al. in [14] presented a performance assessment of the PI, fuzzy PI, and LQR controls for the angular velocity tracking problem. While Bingöl and Paçaci [15] reported a virtual laboratory based on neural networks to control angular velocity of such system. Recent works dealing with the angular velocity trajectory tracking for the DC/DC Buck converter-DC motor system have been reported in [16-21]. Sira-Ramírez and Oliver-Salazar [16] proposed a robust control based on the active disturbance rejection and differential flatness for two configurations of the DC/DC Buck converter-DC motor system. SilvaOrtigoza et al. introduced robust hierarchical controls based on differential flatness $[17,18]$ and sliding mode-PI with flatness in [19]. Likewise, Hernández-Guzmán et al. [20] proposed a sliding mode control and PI for controlling the converter voltage, the armature current, and the angular velocity of the motor. On the other hand, via a sensorless load torque estimation, a control based on the exact tracking error dynamics passive output feedback methodology was proposed by Kumar and Thilagar in [21]. More recently, Khubalkar et al. in [22] presented a stand-alone digital fractional order PID tracking control for the DC/DC Buck converter-DC motor system. Rigatos et al. in [23] designed a flatness-based control to solve the trajectory tracking problem. Another solution was proposed by Nizami et al. in [24], where a neuro-adaptive backstepping control for the angular velocity tracking was developed for the aforementioned system. Other interesting works reported in the last months, on tracking control design for the DC/DC Buck-DC motor system, are [25-29]. Additional works where other topologies of $\mathrm{DC} / \mathrm{DC}$ power converters driven DC motors are [30-32] for the Boost converter, [33] for the Buck-Boost converter, and [34] for the Sepic and Cuk converters.

1.2. Bidirectional Rotation. Due to the principle of operation of the DC/DC power converters, the bidirectional velocity tracking control in DC/DC converters-DC motor systems is not possible using only DC/DC converters. Thus, to overcome this restriction, which has been a topic of interest in the last years, an inverter circuit has been introduced in such systems, leading to DC/DC converter-inverter-DC motor systems. In this direction, Ortigoza et al. presented in [35] the modeling and experimental validation of the DC/DC Buck converter-inverter-DC motor system. While in [36], Ortigoza et al. designed and tested a passivity-based tracking control for a built prototype of the same system. Furthermore, the model and a passivity-based tracking control for the DC/DC Boost converter-inverter-DC motor system were reported in [37] by García-Rodríguez et al. and [38] by Ortigoza et al., respectively. On the other hand, Márquez et al. reported the modeling and experimental validation of the DC/DC Buck-Boost converter-inverter-DC motor system in [39]. Also, for the same system, Hernández-Márquez et al. in [40] solved the regulation problem via a sensorless passivity-based control. Lastly, for the DC/DC Sepic converter-inverter-DC motor system Linares-Flores et al. in [41] solved the regulation problem through a passive control.
After reviewing the literature of the DC motors driven by DC/DC power converters, it was found that different controls have executed the angular velocity regulation and trajectory tracking tasks in two fashions: (i) for unidirectional rotation of the motor shaft [11-34] and (ii) for bidirectional rotation of the motor shaft [35-41]. From the point of view of the practical and industrial applications, [11-34] are limited when compared with [35-41]. Regarding the latter, to the authors' knowledge, for the DC/DC converter-inverter-DC motor systems, robust solution for the trajectory tracking has not been proposed. Thus, the main contribution of this paper is to propose two robust controls based on flatness for the tracking task in the DC/DC Buck converterinverter-DC motor system. The first control considers the system complete dynamics; whereas the second takes into account the dynamics conforming the system separately (i.e., Buck converter and inverter-DC motor), producing a hierarchical controller. The designed controls are experimentally verified on a prototype, showing robustness under parametric uncertainty.

The remainder of the paper is organized as follows. In Section 2, the design of the robust controllers is developed. The experimental results are shown in Section 3. Finally, conclusions are presented in Section 4.

\section{Tracking Controls Based on Differential Flatness}

In this section, two controls are designed with the purpose of carrying out the bidirectional angular velocity trajectory tracking task of a DC/DC Buck converter-DC motor system.

2.1. System Model. The electronic circuit of the system under study is shown in Figure 1. This system, in general, is composed of three stages, namely, a DC/DC Buck converter, a complete bridge inverter, and a DC motor. Unlike the arrangements presented in [11-29], such configuration allows the bidirectional driving of the motor shaft.

The system average model presented in Figure 1, which was deduced and experimentally validated in [35], is given by

$$
\begin{aligned}
L \frac{d i}{d t} & =E u_{1 \mathrm{av}}-v, \\
C \frac{d v}{d t} & =i-\frac{v}{R}-i_{\mathrm{a}} u_{2 \mathrm{av}}, \\
L_{\mathrm{a}} \frac{d i_{\mathrm{a}}}{d t} & =v u_{2 \mathrm{av}}-R_{\mathrm{a}} i_{\mathrm{a}}-k_{\mathrm{e}} \omega, \\
J \frac{d \omega}{d t} & =k_{\mathrm{m}} i_{\mathrm{a}}-b \omega,
\end{aligned}
$$

where $i$ represents the inductor current, $v$ is the capacitor output voltage, $i_{\mathrm{a}}$ is the armature current, $\omega$ is the angular velocity, the voltage source has the constant value $E, L$ is the inductance of the input circuit, $C$ is the capacitance of the output filter, $R$ is the output load, $L_{\mathrm{a}}$ is the armature inductance, $R_{\mathrm{a}}$ is the armature resistance, $J$ is the moment of inertia of the rotor and motor load, $k_{\mathrm{e}}$ is the 


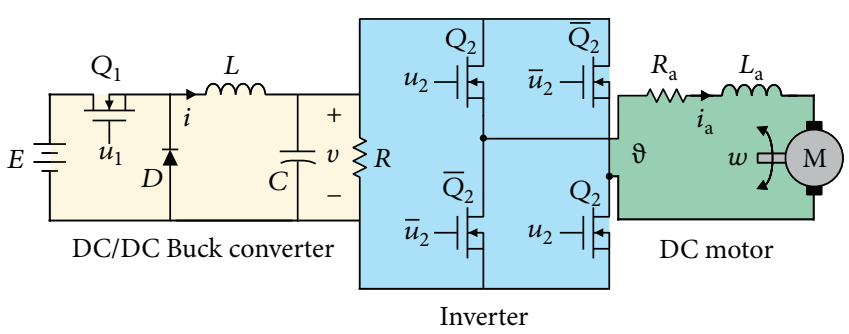

FIGURE 1: DC/DC Buck converter-inverter-DC motor system.

counterelectromotive force constant, $k_{\mathrm{m}}$ is the motor torque constant, and $b$ is the viscous friction coefficient of the motor. Whereas $u_{1 \mathrm{av}}$ and $u_{2 \mathrm{av}}$ represent the system average controls, under the restrictions $u_{1 \mathrm{av}} \in[0,1]$ and $u_{2 \mathrm{av}} \in[-1,1]$, also known as duty cycles.

2.2. Flatness Control: Complete Dynamics. Here, the first flatness control that solves the bidirectional velocity tracking for the DC/DC Buck converter-inverter-DC motor system is designed. This first control considers all the system dynamics, that is, it is based on the fourth-order nonlinear model (1), (2), (3), and (4).

Departing from the work experience related to the DC/DC Buck converter-DC motor, particularly [17, 18], and [19], and from the control objectives, the flat outputs of the system (1), (2), (3), and (4) are proposed as $F_{1}=v$ and $F_{2}=\omega$. Thus, the system differential parametrization is determined by

$$
\begin{aligned}
v & =F_{1}, \\
\omega & =F_{2}, \\
i & =C \dot{F}_{1}+\frac{1}{R} F_{1}+i_{\mathrm{a}} u_{2 \mathrm{av}}, \\
i_{\mathrm{a}} & =\frac{1}{k_{\mathrm{m}}}\left(J \dot{F}_{2}+b F_{2}\right), \\
u_{1 \mathrm{av}} & =\frac{L}{E}\left[C \ddot{F}_{1}+\frac{1}{R} \dot{F}_{1}+\frac{d\left(i_{\mathrm{a}} u_{2 \mathrm{av}}\right)}{d t}+\frac{1}{L} F_{1}\right], \\
u_{2 \mathrm{av}} & =\frac{1}{F_{1}}\left[\frac{J L_{\mathrm{a}}}{k_{\mathrm{m}}} \ddot{F}_{2}+\frac{1}{k_{\mathrm{m}}}\left(b L_{\mathrm{a}}+J R_{\mathrm{a}}\right) \dot{F}_{2}+\left(\frac{b R_{\mathrm{a}}}{k_{\mathrm{m}}}+k_{\mathrm{e}}\right) F_{2}\right] .
\end{aligned}
$$

From the parametrization of $u_{1 \mathrm{av}}(9)$ and $u_{2 \mathrm{av}}$ (10), the following controls are proposed:

$$
\begin{aligned}
& u_{\mathrm{lav}}=\frac{L}{E}\left[C \eta+\frac{1}{R} \dot{F}_{1}+\frac{d\left(i_{\mathrm{a}} u_{2 \mathrm{av}}\right)}{d t}+\frac{1}{L} F_{1}\right], \\
& u_{2 \mathrm{av}}=\frac{1}{F_{1}}\left[\frac{J L_{\mathrm{a}}}{k_{\mathrm{m}}} \mu+\frac{1}{k_{\mathrm{m}}}\left(b L_{\mathrm{a}}+J R_{\mathrm{a}}\right) \dot{F}_{2}+\left(\frac{b R_{\mathrm{a}}}{k_{\mathrm{m}}}+k_{\mathrm{e}}\right) F_{2}\right] .
\end{aligned}
$$

After replacing (11) and (12) in (9) and (10), respectively, the trajectory tracking problem, related to $F_{1}$ and $F_{2}$, is reduced to control the following:

$$
\begin{aligned}
\eta & =\ddot{F}_{1}, \\
\mu & =\ddot{F}_{2} .
\end{aligned}
$$

With the intention of achieving $F_{1} \rightarrow F_{1}^{*}$ and $F_{2} \rightarrow F_{2}^{*}$, with $F_{1}^{*}$ being a desired voltage and $F_{2}^{*}$ a desired angular velocity. Proposals for the auxiliary controls, $\eta$ and $\mu$, that achieve such objectives are the following:

$$
\begin{aligned}
& \eta=\ddot{F}_{1}^{*}-\beta_{2}\left(\dot{F}_{1}-\dot{F}_{1}^{*}\right)-\beta_{1}\left(F_{1}-F_{1}^{*}\right)-\beta_{0} \int_{0}^{t}\left(F_{1}-F_{1}^{*}\right) d \tau, \\
& \mu=\ddot{F}_{2}^{*}-\gamma_{2}\left(\dot{F}_{2}-\dot{F}_{2}^{*}\right)-\gamma_{1}\left(F_{2}-F_{2}^{*}\right)-\gamma_{0} \int_{0}^{t}\left(F_{2}-F_{2}^{*}\right) d \tau .
\end{aligned}
$$

Thus, it is clear that with the selection (15) and (16), the control objective is achieved. Since, after replacing (15) and (16) in (13) and (14), respectively, the tracking errors' dynamics of the closed-loop system are:

$$
\begin{aligned}
& 0=\ddot{e}_{v}+\beta_{2} \ddot{e}_{v}+\beta_{1} \dot{e}_{v}+\beta_{0} e_{v}, \\
& 0=\dddot{e}_{\omega}+\gamma_{2} \ddot{e}_{\omega}+\gamma_{1} \dot{e}_{\omega}+\gamma_{0} e_{\omega},
\end{aligned}
$$

where the tracking errors are defined as

$$
\begin{aligned}
& e_{v}=F_{1}-F_{1}^{*}, \\
& e_{\omega}=F_{2}-F_{2}^{*} .
\end{aligned}
$$

The characteristic polynomials associated with (17) and (18) are determined by

$$
\begin{aligned}
& p_{v}(s)=s^{3}+\beta_{2} s^{2}+\beta_{1} s+\beta_{0}, \\
& p_{\omega}(s)=s^{3}+\gamma_{2} s^{2}+\gamma_{1} s+\gamma_{0} .
\end{aligned}
$$

A convenient selection of the controls gains $\left(\beta_{2}, \beta_{1}, \beta_{0}\right)$ and $\left(\gamma_{2}, \gamma_{1}, \gamma_{0}\right)$ are given by

$$
\begin{aligned}
& \beta_{2}=a_{1}+2 \xi_{1} \omega_{n 1}, \\
& \beta_{1}=2 \xi_{1} \omega_{n 1} a_{1}+\omega_{n 1}^{2}, \\
& \beta_{0}=a_{1} \omega_{n 1}^{2}, \\
& \gamma_{2}=a_{2}+2 \xi_{2} \omega_{n 2}, \\
& \gamma_{1}=2 \xi_{2} \omega_{n 2} a_{2}+\omega_{n 2}^{2}, \\
& \gamma_{0}=a_{2} \omega_{n 2}^{2},
\end{aligned}
$$

which are imposed when matching (20) and (21), term to term, with the following Hurwitz polynomials:

$$
\begin{aligned}
& p_{v_{d}}(s)=\left(s+a_{1}\right)\left(s^{2}+2 \xi_{1} \omega_{n 1} s+\omega_{n 1}^{2}\right), \\
& p_{\omega_{d}}(s)=\left(s+a_{2}\right)\left(s^{2}+2 \xi_{2} \omega_{n 2} s+\omega_{n 2}^{2}\right),
\end{aligned}
$$

with $a_{1}, a_{2}>0, \xi_{1}, \xi_{2}>0$, and $\omega_{n 1}, \omega_{n 2}>0$. 
In consequence, the controls (11) and (12), as long as $v>0$, accomplish $v \rightarrow v^{*}$ and $\omega \rightarrow \omega^{*}$, respectively.

2.3. Flatness-Based Hierarchical Controller: Separate Dynamics. In this section, the second flatness control strategy that executes the bidirectional angular velocity trajectory tracking for the DC/DC Buck converter-inverter-DC motor system (1), (2), (3) and (4) is designed. This strategy is on the basis of a hierarchical control scheme that takes into account the system dynamics separately, that is, a flatness control for the motor and another for the converter. By initially considering that the DC/DC Buck converter and the DC motor operate separately, the hierarchical control structure is the following:

(1) High-level control: this flatness control carries out the bidirectional angular velocity trajectory tracking in the DC motor shaft, that is, $\omega \rightarrow \omega^{*}$.

(2) Low-level control: this flatness control executes the DC/DC Buck converter output voltage tracking, that is, $v \rightarrow v^{*}$.

(3) Integration: this allows the connection between the controls (1) and (2) through the hierarchical control scheme.

(1) DC Motor Control. Since, initially, it is assumed that the Buck converter and DC motor operate separately. Then, from (3) and (4), the motor model is transformed in

$$
\begin{aligned}
L_{\mathrm{a}} \frac{d i_{\mathrm{a}}}{d t} & =\vartheta-R_{\mathrm{a}} i_{\mathrm{a}}-k_{\mathrm{e}} \omega, \\
J \frac{d \omega}{d t} & =k_{\mathrm{m}} i_{\mathrm{a}}-b \omega,
\end{aligned}
$$

where

$$
\vartheta=v u_{2 \mathrm{av}} .
$$

According to [18], the system (25) has as flat output to $\omega$. In consequence, the control $\vartheta$ allows the following representation:

$$
\vartheta=\frac{J L_{\mathrm{a}}}{k_{\mathrm{m}}} \ddot{\omega}+\frac{1}{k_{\mathrm{m}}}\left(b L_{\mathrm{a}}+J R_{\mathrm{a}}\right) \dot{\omega}+\left(\frac{b R_{\mathrm{a}}}{k_{\mathrm{m}}}+k_{\mathrm{e}}\right) \omega .
$$

From (27), after proposing the motor control as

$$
\vartheta=\frac{J L_{\mathrm{a}}}{k_{\mathrm{m}}} \mu+\frac{1}{k_{\mathrm{m}}}\left(b L_{\mathrm{a}}+J R_{\mathrm{a}}\right) \dot{\omega}+\left(\frac{b R_{\mathrm{a}}}{k_{\mathrm{m}}}+k_{\mathrm{e}}\right) \omega,
$$

the angular velocity tracking problem is reduced to control the system:

$$
\mu=\ddot{\omega}
$$

If $\omega^{*}$ is the desired angular velocity, a selection of $\mu$ that accomplishes $\omega \rightarrow \omega^{*}$ is given by

$$
\mu=\ddot{\omega}^{*}-\gamma_{2}\left(\dot{\omega}-\dot{\omega}^{*}\right)-\gamma_{1}\left(\omega-\omega^{*}\right)-\gamma_{0} \int_{0}^{t}\left(\omega-\omega^{*}\right) d \tau,
$$

where $\gamma_{0}, \gamma_{1}$, and $\gamma_{2}$ are the gains of the auxiliary control $\mu$. Defining the tracking error as $e_{\omega}=\omega-\omega^{*}$, after replacing (30) in (29), the error dynamics in closedloop is obtained

$$
\dddot{e}_{\omega}+\gamma_{2} \ddot{e}_{\omega}+\gamma_{1} \dot{e}_{\omega}+\gamma_{0} e_{\omega}=0
$$

whose characteristic polynomial is

$$
p_{\omega}(s)=s^{3}+\gamma_{2} s^{2}+\gamma_{1} s+\gamma_{0}
$$

which is imposed to be stable, via its matching with the Hurwitz polynomial (24), that is,

$$
p_{\omega_{d}}(s)=\left(s+a_{2}\right)\left(s^{2}+2 \xi_{2} \omega_{n 2} s+\omega_{n 2}^{2}\right),
$$

with $a_{2}>0, \xi_{2}>0$, and $\omega_{n 2}>0$. Therefore, the gains $\gamma_{2}, \gamma_{1}$, and $\gamma_{0}$ are given by

$$
\begin{aligned}
& \gamma_{2}=a_{2}+2 \xi_{2} \omega_{n 2}, \\
& \gamma_{1}=2 \xi_{2} \omega_{n 2} a_{2}+\omega_{n 2}^{2}, \\
& \gamma_{0}=a_{2} \omega_{n 2}^{2} .
\end{aligned}
$$

With the aforementioned approach, $\omega \rightarrow \omega^{*}$ when $t \rightarrow \infty$ is achieved.

(2) Buck Converter Control. As it is assumed that there is no connection between the converter and motor. Then, $i_{\mathrm{a}}=0$, from (1) and (2) the Buck converter model is

$$
\begin{aligned}
L \frac{d i}{d t} & =E u_{1 \mathrm{av}}-v, \\
C \frac{d v}{d t} & =i-\frac{v}{R} .
\end{aligned}
$$

According to [18], the flat output of the system (35) is $v$. Thus, $u_{1 \mathrm{av}}$ can be written as:

$$
u_{1 \mathrm{av}}=\frac{L C}{E} \ddot{v}+\frac{L}{R E} \dot{v}+\frac{1}{E} v .
$$

Choosing the control input $u_{1 \mathrm{av}}$, from (36), as

$$
u_{1 \mathrm{av}}=\frac{L C}{E} \eta+\frac{L}{R E} \dot{v}+\frac{1}{E} v .
$$

Then, the voltage tracking in the converter output is reduced to

$$
\eta=\ddot{v}
$$

Thus, a convenient proposal of $\eta$ so that $v \rightarrow v^{*}$, with $v^{*}$ being the converter desired voltage, is

$$
\eta=\ddot{v}^{*}-\beta_{2}\left(\dot{v}-\dot{v}^{*}\right)-\beta_{1}\left(v-v^{*}\right)-\beta_{0} \int_{0}^{t}\left(v-v^{*}\right) d \tau,
$$


where $\beta_{2}, \beta_{1}$, and $\beta_{0}$ are the gains of the auxiliary control $\eta$. Thus, the control (37), with (39), achieves $v \rightarrow v^{*}$ when $t \rightarrow \infty$. This is quickly verified when (39) is replaced in (38). Since, after defining the tracking error $e_{v}=v-v^{*}$, the closed-loop dynamics is obtained

$$
\ddot{e}_{v}+\beta_{2} \ddot{e}_{v}+\beta_{1} \dot{e}_{v}+\beta_{0} e_{v}=0,
$$

whose characteristic polynomial is

$$
p_{v}(s)=s^{3}+\beta_{2} s^{2}+\beta_{1} s+\beta_{0},
$$

which is imposed to be stable through matching it with the Hurwitz polynomial

$$
p_{v_{d}}(s)=\left(s+a_{1}\right)\left(s^{2}+2 \xi_{1} \omega_{n 1} s+\omega_{n 1}^{2}\right),
$$

where $a_{1}>0, \xi_{1}>0$, and $\omega_{n 1}>0$. Hence, the auxiliary control gains are determined by

$$
\begin{aligned}
& \beta_{2}=a_{1}+2 \xi_{1} \omega_{n 1}, \\
& \beta_{1}=2 \xi_{1} \omega_{n 1} a_{1}+\omega_{n 1}^{2}, \\
& \beta_{0}=a_{1} \omega_{n 1}^{2} .
\end{aligned}
$$

(3) Hierarchical Controller. Having carried out the separate control of the subsystems integrating the DC/DC Buck converter-inverter-DC motor system. Now, the hierarchical controller that executes the bidirectional angular velocity trajectory tracking is proposed.

For the DC motor, it was found that the control $\vartheta$ achieving $\omega \rightarrow \omega^{*}$ is determined by

$$
\vartheta=\frac{J L_{\mathrm{a}}}{k_{\mathrm{m}}} \mu+\frac{1}{k_{\mathrm{m}}}\left(b L_{\mathrm{a}}+J R_{\mathrm{a}}\right) \dot{\omega}+\left(\frac{b R_{\mathrm{a}}}{k_{\mathrm{m}}}+k_{\mathrm{e}}\right) \omega,
$$

with $\mu$ defined as

$$
\mu=\ddot{\omega}^{*}-\gamma_{2}\left(\dot{\omega}-\dot{\omega}^{*}\right)-\gamma_{1}\left(\omega-\omega^{*}\right)-\gamma_{0} \int_{0}^{t}\left(\omega-\omega^{*}\right) d \tau .
$$

In turn, $\vartheta$ defined in $(26)$ as

$$
\vartheta=v u_{2 \mathrm{av}},
$$

considers that the voltage $v$ is the power supply of the DC motor inverter circuit. Therefore, the control associated with the inverter is determined by

$$
u_{2 \mathrm{av}}=\frac{\vartheta}{v} .
$$

On the other hand, the control accomplishing $v \rightarrow v^{*}$ was defined as

$$
u_{\mathrm{lav}}=\frac{L C}{E} \eta+\frac{L}{R E} \dot{v}+\frac{1}{E} v,
$$

with $\eta$ given by

$$
\eta=\ddot{v}^{*}-\beta_{2}\left(\dot{v}-\dot{v}^{*}\right)-\beta_{1}\left(v-v^{*}\right)-\beta_{0} \int_{0}^{t}\left(v-v^{*}\right) d \tau .
$$

Thus, the hierarchical controller is determined by (48) and (47), as long as $v>0$, obtaining $v \rightarrow v^{*}$ and $\omega \rightarrow \omega^{*}$, respectively.

\section{Experimental Results in Closed-Loop}

Here, the experimental results in closed-loop of the flatness controls designed in Section 2 are presented. The controls robustness is verified under abrupt variations in the system parameters. In the experimental development, MATLABSimulink and a dSPACE DS1104 board are used.

3.1. Experimental Setup. The experimental setup was developed using the general connection diagram shown in Figure 2. In the diagram presented in Figure 2 the following blocks are distinguished:

(i) Bidirectional DC/DC Buck converter-DC motor system: this block corresponds to the system under study and is composed of three stages, namely, a Buck power converter, an inverter, and a DC motor. The nominal values of the Buck converter parameters are as follows:

$$
\begin{aligned}
& L=4.94 \mathrm{mH}, \\
& R=64 \Omega, \\
& C=114.4 \mu \mathrm{F}, \\
& E=42 \mathrm{~V} .
\end{aligned}
$$

The inverter allows obtaining the bidirectional angular velocities in the motor shaft. The driving of the inverter transistors is carried out by two IR2113. Lastly, the used DC motor corresponds to the GNM5440E-G3.1 whose nominal parameters are as follows:

$$
\begin{aligned}
L_{\mathrm{a}} & =2.22 \mathrm{mH}, \\
k_{\mathrm{e}} & =120.1 \times 10^{-3} \mathrm{~N} \cdot \mathrm{m} / \mathrm{A}, \\
R_{\mathrm{a}} & =0.965 \Omega, \\
k_{\mathrm{m}} & =120.1 \times 10^{-3} \mathrm{~V} \cdot \mathrm{s} / \mathrm{rad}, \\
J & =118.2 \times 10^{-3} \mathrm{~kg} \cdot \mathrm{m}^{2}, \\
b & =129.6 \times 10^{-3} \mathrm{~N} \cdot \mathrm{m} \cdot \mathrm{s} / \mathrm{rad} .
\end{aligned}
$$

(ii) Flatness controls: in this block, the differential flatness controls are programmed via MATLABSimulink. That is, the controls (11) and (12) (based on the complete dynamics) and (47) and (48) (based on the separate dynamics of the system) are experimentally implemented. The gain parameters associated with the differential flatness controls, (11), (12) and (47), (48), are defined as 
Bidirectional DC/DC Buck converter-DC motor system
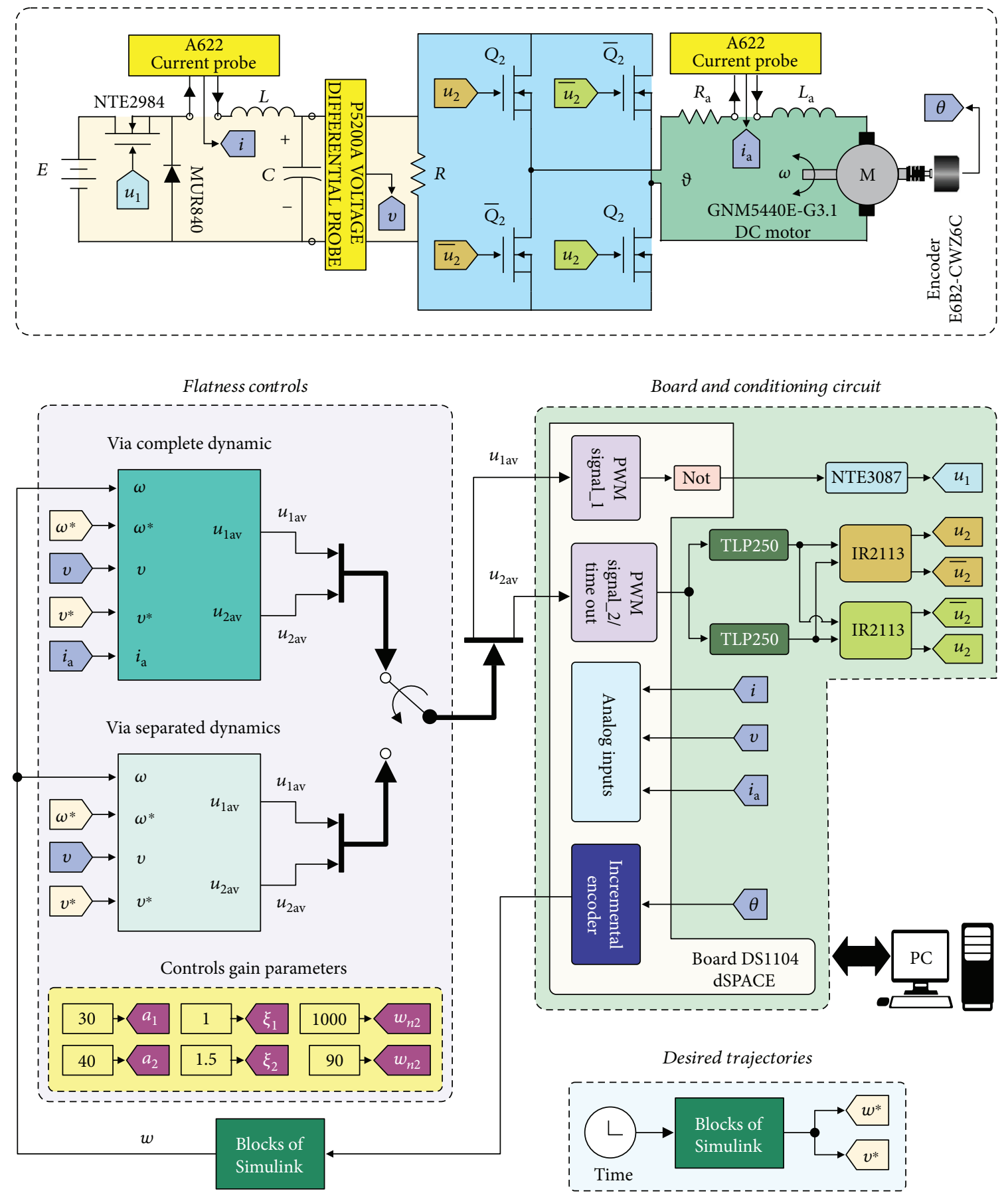

FIGURE 2: General diagram of the experimental setup connections.

$$
\begin{aligned}
a_{1} & =30, \\
\xi_{1} & =1, \\
\omega_{n 1} & =1000, \\
a_{2} & =40, \\
\xi_{2} & =1.5, \\
\omega_{n 2} & =90 .
\end{aligned}
$$

Notice that the gain definitions related to the controls, given by (22), (34), and (43) are equal.

(iii) Desired trajectories: in this block, the desired trajectories $\omega^{*}$ and $v^{*}$ are programmed. For the DC motor, the following bidirectional trajectory is proposed:

$$
\omega^{*}(t)=A \sin \left(\frac{2 \pi}{P} t\right)
$$


with a period $P=20 / 3 \mathrm{~s}$ and an amplitude $A=$ $13 \mathrm{rad} / \mathrm{s}$. Whereas for the Buck converter, the trajectory is defined as

$$
v^{*}(t)=\bar{v}_{i}\left(t_{i}\right)+\left[\bar{v}_{f}\left(t_{f}\right)-\bar{v}_{i}\left(t_{i}\right)\right] \psi\left(t, t_{i}, t_{f}\right) .
$$

That is, the desired trajectory $v^{*}$ smoothly interpolates between the initial voltage $\bar{v}_{i}=24 \mathrm{~V}$ and the final one $\bar{v}_{f}=30 \mathrm{~V}$ in the time interval $\left[t_{i}, t_{f}\right]=[1 \mathrm{~s}, 2 \mathrm{~s}]$ through the Bézier polynomial $\psi$, defined by

$$
\psi\left(t, t_{i}, t_{f}\right)=\left\{\begin{array}{l}
0, \quad t \leq t_{i}, \\
\left(\frac{t-t_{i}}{t_{f}-t_{i}}\right)^{3}\left[20-45\left(\frac{t-t_{i}}{t_{f}-t_{i}}\right)+36\left(\frac{t-t_{i}}{t_{f}-t_{i}}\right)^{2}-10\left(\frac{t-t_{i}}{t_{f}-t_{i}}\right)^{3}\right], \quad t \in\left(t_{i}, t_{f}\right), \\
1, \quad t \geq t_{f} .
\end{array}\right.
$$

(iv) Board and conditioning circuit: this block electrically isolates the DS1104 board from the power stage, through the NTE3087 and TLP250 optocouplers. Furthermore, this block properly drives the Buck converter and inverter when generating, by means of the PWM1 and PWM2, the switched inputs $u_{1}$ and $u_{2}$, respectively. Also, in this block, the measurement of the variables $i, v, i_{\mathrm{a}}$, and $\omega$ is carried out. Two current probes A622 are used to measure $i$ and $i_{\mathrm{a}}$. While the voltage probe $\mathrm{P} 5200 \mathrm{~A}$ is employed to read the voltage $v$. Lastly, $\omega$ is obtained via the E6B2-CWZ6C encoder and Simulink blocks.

3.2. Experimental Results. In order to obtain the experimental results, the connection diagram shown in Figure 2 has been used. This shows the interconnections of the bidirectional DC/DC Buck converter-DC motor system with MATLABSimulink and the DS1104 board.

With the intention of evaluating the performance of the designed controls, the following abrupt changes in the system parameters $E, R, L$, and $C$ have been considered:

$$
\begin{aligned}
& E_{\mathrm{m}}=\left\{\begin{array}{l}
E, \quad 0 \mathrm{~s} \leq t<2.5 \mathrm{~s}, \\
70 \% E, \quad 2.5 \mathrm{~s} \leq t<5 \mathrm{~s}, \\
E, \quad 5 \mathrm{~s} \leq t \leq 20 \mathrm{~s},
\end{array}\right. \\
& R_{\mathrm{m}}=\left\{\begin{array}{l}
R, \quad 0 \mathrm{~s} \leq t<7.5 \mathrm{~s}, \\
14 \% R, \quad 7.5 \mathrm{~s} \leq t<10 \mathrm{~s}, \\
R, \quad 10 \mathrm{~s} \leq t \leq 20 \mathrm{~s},
\end{array}\right. \\
& L_{\mathrm{m}}=\left\{\begin{array}{l}
L, \quad 0 \mathrm{~s} \leq t<12.5 \mathrm{~s}, \\
30 \% L, \quad 12.5 \mathrm{~s} \leq t<15 \mathrm{~s}, \\
L, \quad 15 \mathrm{~s} \leq t \leq 20 \mathrm{~s},
\end{array}\right. \\
& C_{\mathrm{m}}=\left\{\begin{array}{l}
C, \quad 0 \mathrm{~s} \leq t<17.5 \mathrm{~s}, \\
300 \% C, \quad 17.5 \mathrm{~s} \leq t \leq 20 \mathrm{~s} .
\end{array}\right.
\end{aligned}
$$

Figure 3 shows the experimental results in closed-loop when the abrupt changes (56) are considered. Whereas, Figure 4 depicts the experimental results when an abrupt load variation, via a brake system, is applied in $8 \mathrm{~s} \leq t \leq 15 \mathrm{~s}$. In both figures, the results associated with the control based on the complete dynamics, that is, (11) and (12), correspond to $\omega_{\mathrm{cd}}, i_{\mathrm{a}_{\mathrm{cd}}}, u_{2 \mathrm{av}_{\mathrm{cd}}}, v_{\mathrm{cd}}, i_{\mathrm{cd}}$, and $u_{\mathrm{av}_{\mathrm{cd}}}$. While the results related to the control based on the separate dynamics, that is, (47) and (48), are $\omega_{\mathrm{sd}}, i_{\mathrm{asd}_{\mathrm{sd}}}, u_{2 \mathrm{av}_{\mathrm{sd}}}, v_{\mathrm{sd}}, i_{\mathrm{sd}}$, and $u_{\mathrm{aav}_{\mathrm{sd}}}$.

As can be observed in Figures 3 and 4, the results are satisfactory for both controls, since it is achieved that $\omega \rightarrow \omega^{*}$ and $v \rightarrow v^{*}$ even when abrupt changes in the system parameters and an abrupt load variation are taken into account. Thus, the robustness of the controls is shown. On the other hand, the controls $u_{1 \mathrm{av}}$ and $u_{2 \mathrm{av}}$ are not saturated when executing the system tracking task. That is, $u_{1 \mathrm{av}} \in[0,1]$ and $u_{2 \mathrm{av}} \in[-1,1]$ in all the experimental results.

Lastly, although in general the two controls show good performance, the authors consider that the scheme based on the hierarchical approach, that is, (47) and (48), is more simple to design because the system (1), (2), (3), and (4) is separated in two subsystems.

\section{Conclusions}

In this paper, two flatness-based robust controls for the bidirectional angular velocity trajectory tracking problem of the DC/DC Buck converter-inverter-DC motor system were proposed. The first control considers the system complete dynamics. Whereas, the second separates the dynamics of the system, which later are joined through a hierarchical controller. The performance of the proposed controls was verified through experiments with a built prototype, MATLAB-Simulink, and a DS1104 board. The results shown that the proposed controls satisfactorily execute the trajectory tracking task even when abrupt changes on the system parameters are considered. Thus, the robustness of the flatness-based controls was exhibited. It is noteworthy that the tested uncertainties do not simultaneously occur in practice. However, they were presented with the purpose of 


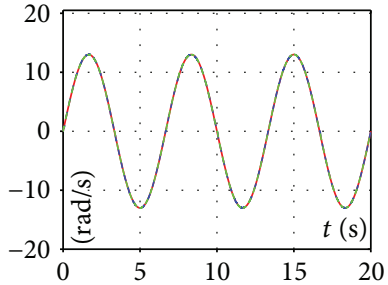

$$
\begin{array}{ll}
- & \omega^{*} \\
- & \omega_{c d} \\
- & \omega_{s d}
\end{array}
$$

(a)

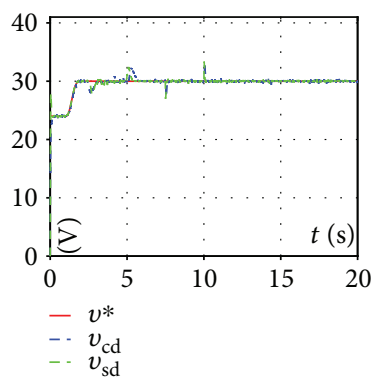

(d)

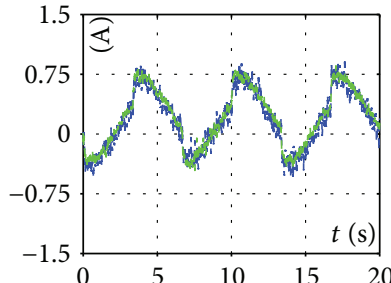

$--i_{\mathrm{a}_{\mathrm{cd}}}$
$--i_{\mathrm{a}_{\mathrm{sd}}}$

(b)

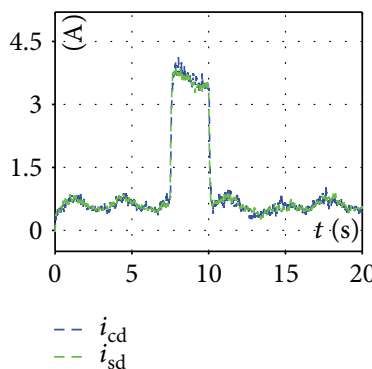

(e)

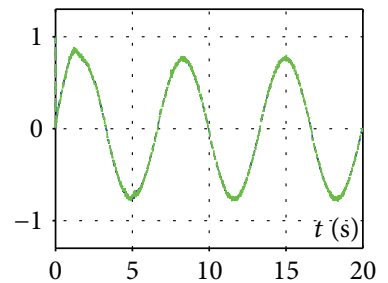

$\begin{array}{ll}-- & u_{2 \mathrm{av}} \mathrm{cd} \\ -- & u_{2 \mathrm{av}} \\ & \mathrm{av}_{\mathrm{sd}}\end{array}$

(c)

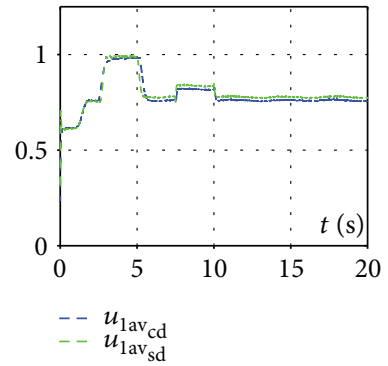

(f)

Figure 3: Experimental results of controls (11), (12) and (47), (48) when abrupt changes in $E_{\mathrm{m}}, R_{\mathrm{m}}, L_{\mathrm{m}}$, and $C_{\mathrm{m}}$ are considered.

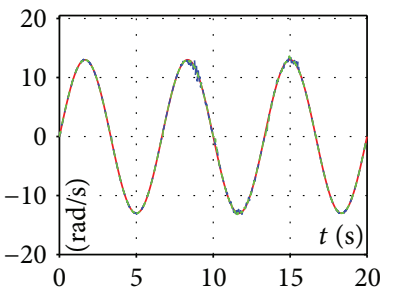

$\begin{aligned}- & \omega^{*} \\ -- & \omega\end{aligned}$

-. $\omega_{\mathrm{cd}}$

(a)

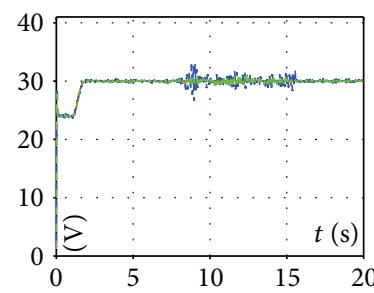

$\begin{array}{ll}- & v^{*} \\ -- & v_{\mathrm{cd}}\end{array}$

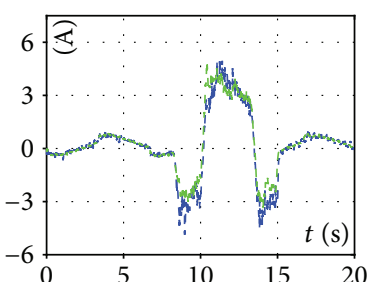

$--i_{\mathrm{a}_{\mathrm{cd}}}$
$--i_{\mathrm{a}_{\mathrm{sd}}}$

(b)

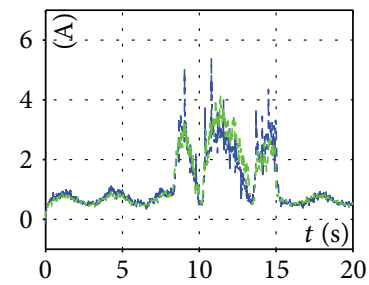

$--i_{\mathrm{cd}}$

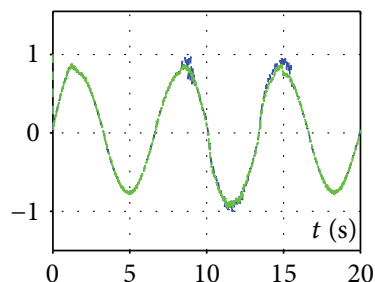

$\begin{array}{ll}-- & u_{2 \mathrm{av}_{\mathrm{cd}}} \\ -- & u_{2 \mathrm{av}}\end{array}$

(c)

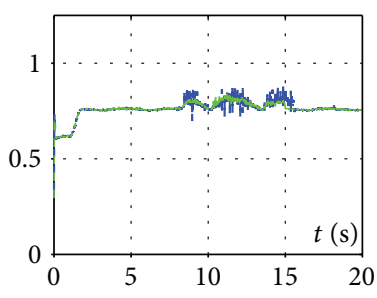

$\begin{array}{ll}-- & u_{1 \mathrm{av}} \mathrm{cd} \\ -- & u_{1 \mathrm{av}}\end{array}$

(f)

Figure 4: Experimental results of controls (11), (12) and (47), (48) when an abrupt load change is applied.

showing the possible industrial application of the herein designed controls.

\section{Data Availability}

The data used to support the findings of this study are available from the corresponding author upon request.

\section{Conflicts of Interest}

The authors declare that the research was conducted in the absence of any commercial, financial, or personal relationships that could be construed as a potential conflict of interests. 


\section{Acknowledgments}

The authors thank the editor and the anonymous reviewers for the time spent in the revision of the manuscript. Their valuable comments helped to significantly improve the quality of the paper. This work was supported by Secretaría de Investigación y Posgrado del Instituto Politécnico Nacional, México. The work of Eduardo HernándezMárquez, José Rafael García-Sánchez, and Mayra AntonioCruz has been supported by CONACYT-México and BEIFI scholarships. Likewise, Eduardo Hernández-Márquez thanks the Instituto Tecnológico Superior de Poza Rica for the support given to study Ph.D. program at CIDETECIPN. Ramón Silva-Ortigoza, Hind Taud, and Mariana Marcelino-Aranda acknowledge financial support from IPN programs EDI and SIBE and from SNI-México. Finally, Victor Manuel Hernández-Guzmán thanks the SNI-México for financial support.

\section{References}

[1] J. Popović-Gerber, J. A. Oliver, N. Cordero et al., "Power electronics enabling efficient energy usage: energy savings potential and technological challenges," IEEE Transactions on Power Electronics, vol. 27, no. 5, pp. 2338-2353, 2012.

[2] R. Fuger, A. Matsekh, J. Kells, D. B. T. Sercombe, and A. Guina, "A superconducting homopolar motor and generator-new approaches," Superconductor Science and Technology, vol. 29, no. 3, article 034001, 2016.

[3] H. Sira-Ramírez and R. Silva-Ortigoza, Control Design Techniques in Power Electronics Devices, Springer-Verlag, London, UK, 2006.

[4] T. Strasser, F. Andrén, J. Kathan et al., "A review of architectures and concepts for intelligence in future electric energy systems," IEEE Transactions on Industrial Electronics, vol. 62, no. 4, pp. 2424-2438, 2015.

[5] S. Jain, A. K. Thopukara, R. Karampuri, and V. T. Somasekhar, "A single-stage photovoltaic system for a dual-inverter-fed open-end winding induction motor drive for pumping applications," IEEE Transactions on Power Electronics, vol. 30, no. 9, pp. 4809-4818, 2015.

[6] X. Z. Gao, Z. X. Hou, Z. Guo, and X. Q. Chen, "Reviews of methods to extract and store energy for solar-powered aircraft," Renewable and Sustainable Energy Reviews, vol. 44, pp. 96-108, 2015.

[7] P. A. Plonski, J. V. Hook, and V. Isler, "Environment and solar map construction for solar-powered mobile systems," IEEE Transactions on Robotics, vol. 32, no. 1, pp. 70-82, 2016.

[8] M. Gadalla and S. Zafar, "Analysis of a hydrogen fuel cell-PV power system for small UAV," International Journal of Hydrogen Energy, vol. 41, no. 15, pp. 6422-6432, 2016.

[9] S. Ademi and M. Jovanovic, "Control of doubly-fed reluctance generators for wind power applications," Renewable Energy, vol. 85, pp. 171-180, 2016.

[10] J. R. García-Sánchez, R. Silva-Ortigoza, S. Tavera-Mosqueda et al., "Tracking control for mobile robots considering the dynamics of all their subsystems: experimental implementation," Complexity, vol. 2017, Article ID 5318504, 18 pages, 2017.
[11] S. E. Lyshevski, Electromechanical Systems, Electric Machines, and Applied Mechatronics, CRC Press, Boca Raton, FL, USA, 1999.

[12] I. Boldea and S. A. Nasar, Electric Drives, CRC Press, Boca Raton, FL, USA, 1999.

[13] J. Linares-Flores, Control Suave de Velocidad de Motores de CD Mediante Convertidores de Potencia CD/CD, [Ph.D. thesis], Sección de Mecatrónica del Departamento de Ingeniería Eléctrica del CINVESTAV-IPN, Mexico City, Mexico, 2006.

[14] M. A. Ahmad, R. M. T. Raja Ismail, and M. S. Ramli, "Control strategy of Buck converter driven DC motor: a comparative assessment," Australian Journal of Basic and Applied Sciences, vol. 4, no. 10, pp. 4893-4903, 2010.

[15] O. Bingöl and S. Paçaci, "A virtual laboratory for neural network controlled DC motors based on a DC-DC Buck converter," International Journal of Engineering Education, vol. 28, no. 3, pp. 713-723, 2012.

[16] H. Sira-Ramírez and M. A. Oliver-Salazar, "On the robust control of Buck-converter DC-motor combinations," IEEE Transactions on Power Electronics, vol. 28, no. 8, pp. 39123922, 2013.

[17] R. Silva-Ortigoza, J. R. García-Sánchez, J. M. Alba-Martínez et al., "Two-stage control design of a Buck converter/DC motor system without velocity measurements via a $\Sigma-\Delta$-modulator," Mathematical Problems in Engineering, vol. 2013, Article ID 929316, 11 pages, 2013.

[18] R. Silva-Ortigoza, C. Márquez-Sánchez, F. Carrizosa-Corral, M. Antonio-Cruz, J. M. Alba-Martínez, and G. SaldañaGonzález, "Hierarchical velocity control based on differential flatness for a DC/DC Buck converter-DC motor system," Mathematical Problems in Engineering, vol. 2014, Article ID 912815, 12 pages, 2014.

[19] R. Silva-Ortigoza, V. M. Hernández-Guzmán, M. AntonioCruz, and D. Muñoz-Carrillo, "DC/DC Buck power converter as a smooth starter for a DC motor based on a hierarchical control," IEEE Transactions on Power Electronics, vol. 30, no. 2, pp. 1076-1084, 2015.

[20] V. M. Hernández-Guzmán, R. Silva-Ortigoza, and D. MuñozCarrillo, "Velocity control of a brushed DC-motor driven by a DC to DC Buck power converter," International Journal of Innovative Computing, Information and Control, vol. 11, no. 2, pp. 509-521, 2015.

[21] S. G. Kumar and S. H. Thilagar, "Sensorless load torque estimation and passivity based control of Buck converter fed DC motor," The Scientific World Journal, vol. 2015, Article ID 132843, 15 pages, 2015.

[22] S. Khubalkar, A. Chopade, A. Junghare, M. Aware, and S. Das, "Design and realization of stand-alone digital fractional order PID controller for Buck converter fed DC motor," Circuits, Systems, and Signal Processing, vol. 35, no. 6, pp. 21892211, 2016.

[23] G. Rigatos, P. Siano, P. Wira, and M. Sayed-Mouchaweh, "Control of DC-DC converter and DC motor dynamics using differential flatness theory," Intelligent Industrial Systems, vol. 2, no. 4, pp. 371-380, 2016.

[24] T. K. Nizami, A. Chakravarty, and C. Mahanta, "Design and implementation of a neuro-adaptive backstepping controller for Buck converter fed PMDC-motor," Control Engineering Practice, vol. 58, pp. 78-87, 2017.

[25] A. Chakravarty, T. K. Nizami, and C. Mahanta, "Real time implementation of an adaptive backstepping control of Buck 
converter PMDC-motor combinations," in 2017 Indian Control Conference (ICC), pp. 277-282, Guwahati, India, January 2017.

[26] T. K. Roy, L. C. Paul, M. I. Sarkar, M. F. Pervej, and F. K. Tumpa, "Adaptive controller design for speed control of DC motors driven by a DC-DC Buck converter," in 2017 International Conference on Electrical, Computer and Communication Engineering (ECCE), pp. 100-105, Cox's Bazar, Bangladesh, February 2017.

[27] M. A. Ahmad and R. M. T. Raja Ismail, "A data-driven sigmoid-based PI controller for Buck-converter powered DC motor," in 2017 IEEE Symposium on Computer Applications \& Industrial Electronics (ISCAIE), pp. 81-86, Langkawi Island, Malaysia, April 2017.

[28] T. K. Nizami, A. Chakravarty, and C. Mahanta, "A fast learning neuro adaptive control of Buck converter driven PMDC motor: design, analysis and validation," IFACPapersOnLine, vol. 50, no. 1, pp. 37-42, 2017.

[29] H. Wu, L. Zhang, J. Yang, and S. Li, "Model predictive control for DC-DC Buck power converter-DC motor system with uncertainties using GPI observer," in 2017 36th Chinese Control Conference (CCC), pp. 4906-4911, Dalian, China, July 2017.

[30] J. Linares-Flores, J. Reger, and H. Sira-Ramirez, "Load torque estimation and passivity-based control of a Boost-converter/ DC-motor combination," IEEE Transactions on Control Systems Technology, vol. 18, 2010.

[31] A. T. Alexandridis and G. C. Konstantopoulos, "Modified PI speed controllers for series-excited DC motors fed by DC/ DC Boost converters," Control Engineering Practice, vol. 23, pp. 14-21, 2014.

[32] G. C. Konstantopoulos and A. T. Alexandridis, "Enhanced control design of simple DC-DC Boost converter-driven DC motors: analysis and implementation," Electric Power Components and Systems, vol. 43, no. 17, pp. 1946-1957, 2015.

[33] J. Linares-Flores, J. L. Barahona-Avalos, H. Sira-Ramírez, and M. A. Contreras-Ordaz, "Robust passivity-based control of a Buck-Boost-converter/DC-motor system: an active disturbance rejection approach," IEEE Transactions on Industry Applications, vol. 48, no. 6, pp. 2362-2371, 2012.

[34] E. E. Jiménez-Toribio, A. A. Labour-Castro, F. MuñizRodríguez, H. R. Pérez-Hernández, and E. I. Ortiz-Rivera, "Sensorless control of Sepic and Cuk converters for DC motors using solar panels," in 2009 IEEE International Electric Machines and Drives Conference, pp. 1503-1510, Miami, FL, USA, May 2009.

[35] R. S. Ortigoza, J. N. A. Juarez, J. R. G. Sanchez, M. A. Cruz, V. M. H. Guzman, and H. Taud, "Modeling and experimental validation of a bidirectional DC/DC Buck power electronic converter-DC motor system," IEEE Latin America Transactions, vol. 15, no. 6, pp. 1043-1051, 2017.

[36] R. S. Ortigoza, J. N. A. Juarez, J. R. G. Sanchez, V. M. H. Guzman, C. Y. S. Cervantes, and H. Taud, "A sensorless passivity-based control for the DC/DC Buck converterinverter-DC motor system," IEEE Latin America Transactions, vol. 14, no. 10, pp. 4227-4234, 2016.

[37] V. H. García-Rodríguez, R. Silva-Ortigoza, E. HernándezMárquez, J. R. García-Sánchez, M. Ponce-Silva, and G. Saldaña-González, "A DC motor driven by a DC/DC Boost converter-inverter: modeling and simulation," in 2016 International Conference on Mechatronics, Electronics and
Automotive Engineering (ICMEAE), pp. 78-83, Cuernavaca, Morelos, Mexico, November 2016.

[38] R. S. Ortigoza, V. H. G. Rodriguez, E. H. Marquez et al., "A trajectory tracking control for a Boost converter-inverterDC motor combination," IEEE Latin America Transactions, vol. 16, no. 4, pp. 1008-1014, 2018.

[39] E. H. Marquez, R. S. Ortigoza, J. R. G. Sanchez, V. H. G. Rodriguez, and J. N. A. Juarez, "A new "DC/DC Buck-Boost converter-DC motor" system: modeling and experimental validation," IEEE Latin America Transactions, vol. 15, no. 11, pp. 2043-2049, 2017.

[40] E. Hernández-Márquez, R. Silva-Ortigoza, C. A. Avila-Rea et al., "Regulation of the DC/DC Buck-Boost converterinverter-DC motor system: sensorless passivity based control," in 2017 International Conference on Mechatronics, Electronics and Automotive Engineering (ICMEAE), pp. 88-92, Cuernavaca, Mexico, November 2017.

[41] J. Linares-Flores, H. Sira-Ramírez, E. F. Cuevas-López, and M. A. Contreras-Ordaz, "Sensorless passivity based control of a DC motor via a solar powered Sepic converter-full bridge combination," Journal of Power Electronics, vol. 11, no. 5, pp. 743-750, 2011. 


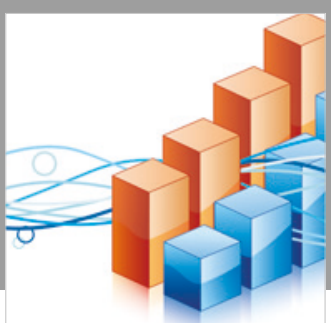

Advances in

Operations Research

\section{-n-m}
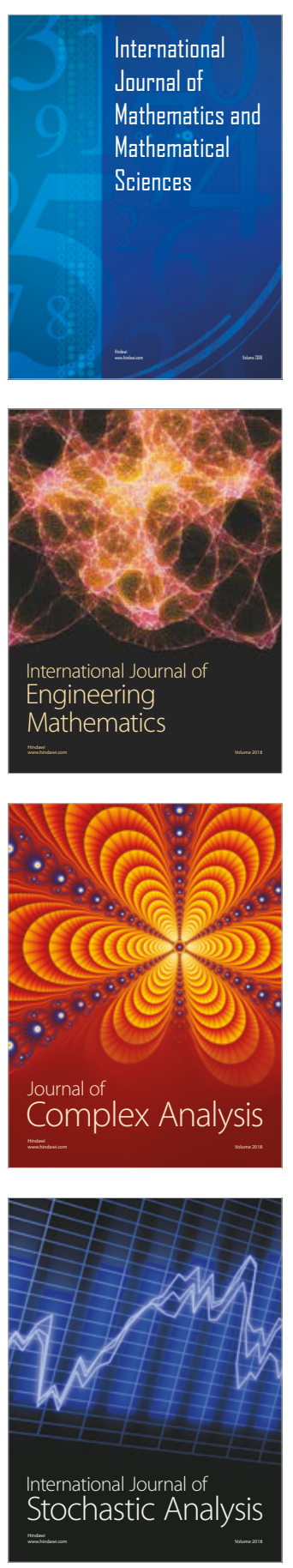
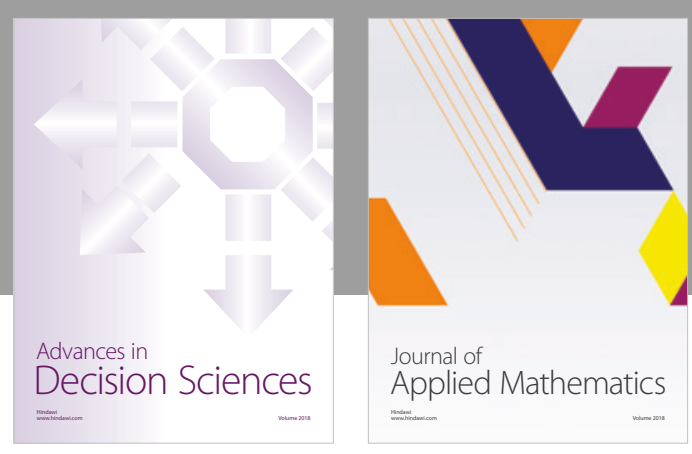

Journal of

Applied Mathematics
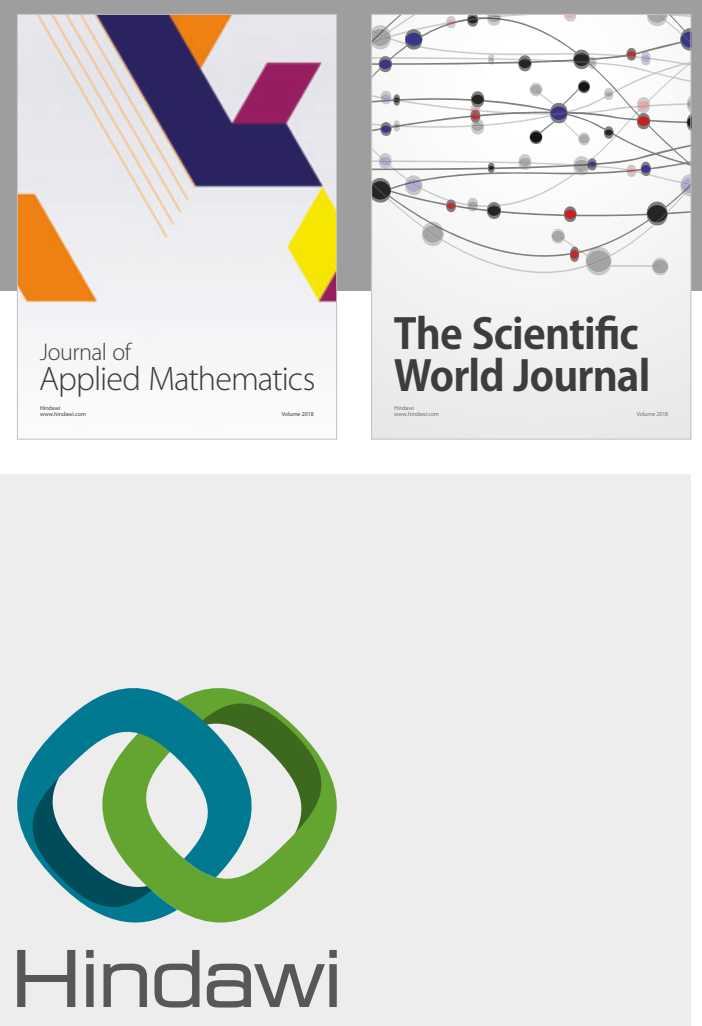

Submit your manuscripts at

www.hindawi.com

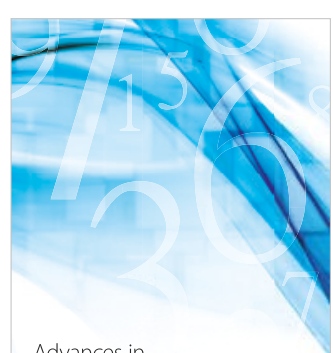

Advances in
Numerical Analysis
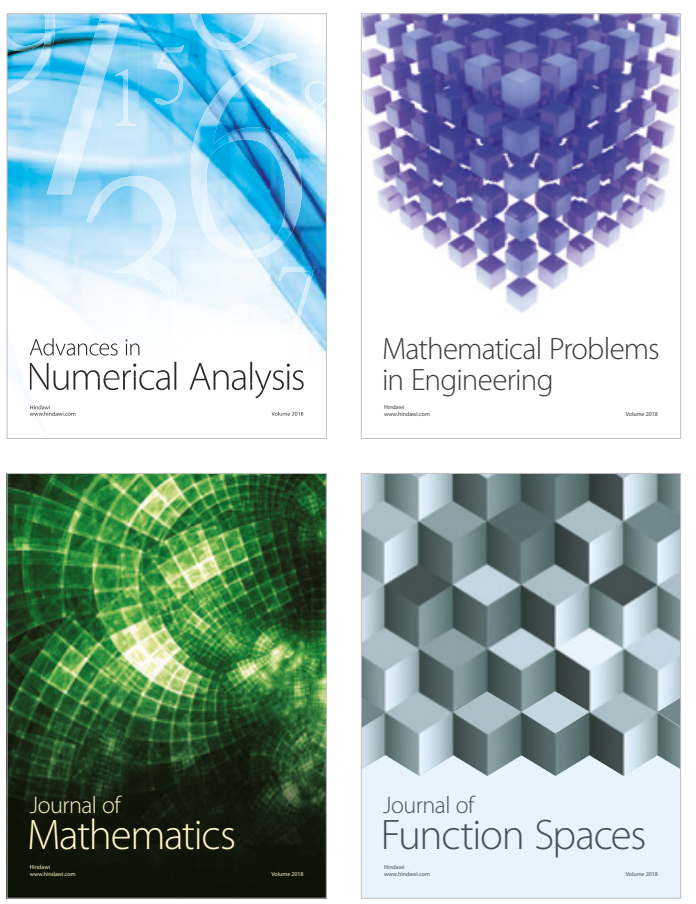

Mathematical Problems in Engineering

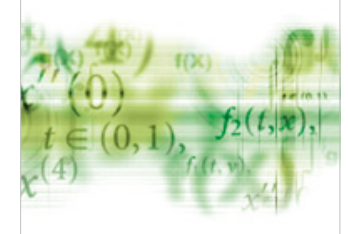

International Journal of

Differential Equations

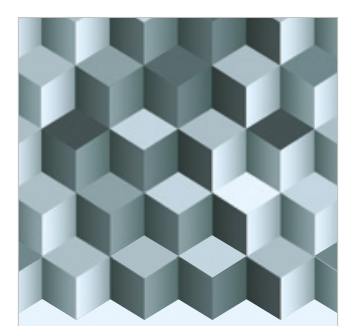

Journal of

Function Spaces
The Scientific

World Journal

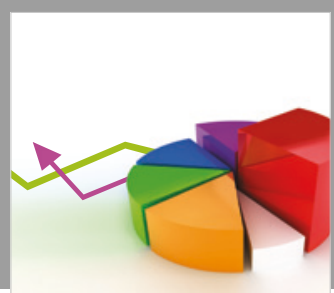

Journal of

Probability and Statistics
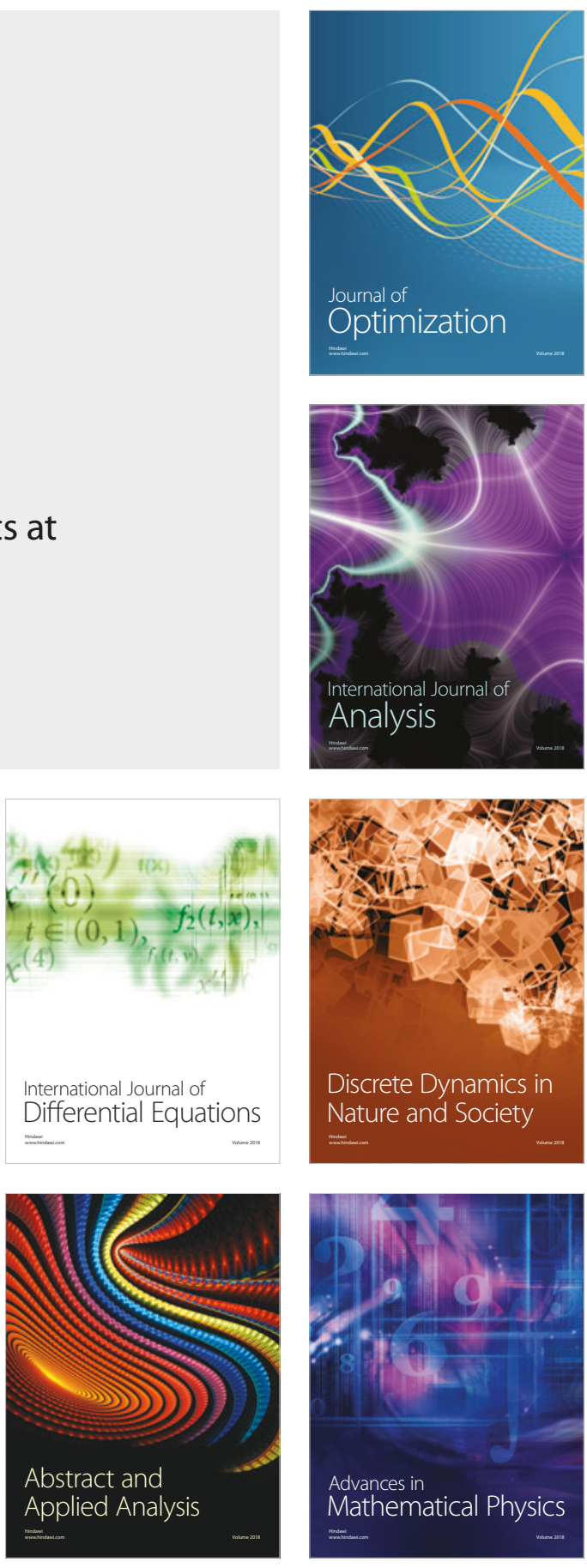